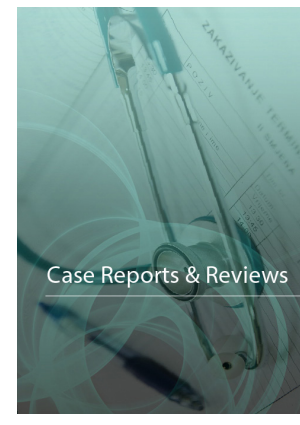

Correspondence

Youichi Yanagawa

1129 Nagaoka, Izunokuni City, Shizuoka, 410-2295, Japan

E-mail: yyanaga@juntendo.ac.jp

Tel: +81-055-948-3111

- Received Date: 11 Feb 2020;

- Accepted Date: 18 Feb 2020;

- Publication Date: 22 Feb 2020

Keywords

lung edema; methemoglobinemia; charcoal burning suicide

\section{Copyright}

(C) 2020 Science Excel. This is an openaccess article distributed under the terms of the Creative Commons Attribution 4.0 International license.

\title{
A case of lung edema and methemoglobinemia after attempted suicide by charcoal burning
}

\author{
Youichi Yanagawa ${ }^{1 *}$ and Yasuhiro Suzuki ${ }^{2}$ \\ 'Department of Acute Critical Care Medicine, Shizuoka Hospital, Juntendo University, Japan \\ ${ }^{2}$ Department of Neurology, Juntendo University, Shizuoka Saiseikai General Hospital, Japan
}

\begin{abstract}
The patient was a 24-year-old woman with a history of depression and panic disorder. She attempted to commit suicide by burning charcoal in a sealed bathroom by placing charcoal on a steel mesh grate and igniting it from the bottom using a barbecue stove. The bathroom was filled with white smoke. After experiencing dyspnea, she opened the door of the bathroom and telephoned a friend who called an ambulance. She was transported to a local hospital by the ambulance. On arrival, she showed mild consciousness disturbance. A physiological examination revealed no specific findings. Thoracic computed tomography showed a diffuse patchy ground glass appearance. The results of an arterial blood gas analysis revealed carboxyhemoglobinemia and methemoglobinemia. She was diagnosed with carbon monoxide poisoning, methemoglobinemia and chemical lung edema. She was transferred to another hospital for hyperbaric oxygen therapy. After 5 days of hyperbaric oxygen therapy, she was discharged without sequelae. This is the first case of carbon monoxide poisoning, methemoglobinemia and lung edema without heart failure after an attempted suicide by charcoal burning. The mechanism underlying the development of methemoglobinemia and lung edema is discussed.
\end{abstract}

\section{Introduction}

A report from the Ministry of Health, Labour and Welfare regarding suicides in the Heisei 27 fiscal year (nearly 2015) showed that hanging was the most common method of suicide employed by males, followed by charcoal burning, while hanging followed by falling, drowning and charcoal burning were the most common methods of suicide employed by females [1]. Charcoal burning is a common suicide method in Asian countries, but is rare in the West [2]. Charcoal burning suicide, which involves burning charcoal in a sealed room, causes death by carbon monoxide poisoning. We herein report a case in which a patient developed lung edema and methemoglobinemia after attempting suicide by burning charcoal on a steel mesh grate. There are no other reports of these conditions in patients who have attempted suicide by this method.

\section{Case presentation}

The patient was a 24 -year-old woman with a history of depression, panic disorder and attempted suicide by hanging, who was treated with paroxetine and zolpidem. She attempted to commit suicide by burning charcoal in a sealed bathroom by placing some charcoal on a steel mesh grate and igniting it from the bottom using a barbecue stove (Figure 1). The bathroom was filled with white smoke. After experiencing dyspnea, she opened the door of the bathroom and telephoned a friend who called an ambulance. Hydrogen sulfate gas was not detected when firefighters checked her room using a gasdetecting tube. No chlorine detergent was found in the bathroom. She was transported to Numazu City Hospital with $15 \mathrm{~L}$ per minute of oxygen mask by the ambulance. On arrival, her vital signs were as follows: Glasgow Coma Scale, E3V5M6; blood pressure, $98 / 50 \mathrm{mmHg}$; heart rate, 64 beats per minute; respiratory rate 30 breaths per minute; body temperature, $36.3^{\circ} \mathrm{C}$. A physiological examination revealed no specific findings. Electrocardiography, cardiac echography and chest roentgenography revealed no specific findings.

Whole-body computed tomography showed a diffuse patchy ground glass appearance (Figure 2). The results of an arterial blood gas analysis, cell blood count and biochemical study are shown in Table 1. She was diagnosed with carbon monoxide poisoning, methemoglobinemia and chemical lung edema without heart failure. She was transferred to Shizuoka Saiseikai General Hospital for hyperbaric oxygen therapy in a multiplace chamber. After 5 days of hyperbaric oxygen therapy with 3 atmospheres of absolute pressure, she was discharged without sequelae.

\section{Discussion}

This is the first reported case in which attempted suicide by burning charcoal on a steel mesh grate was associated with carbon monoxide poisoning, methemoglobinemia and lung edema without heart failure. 


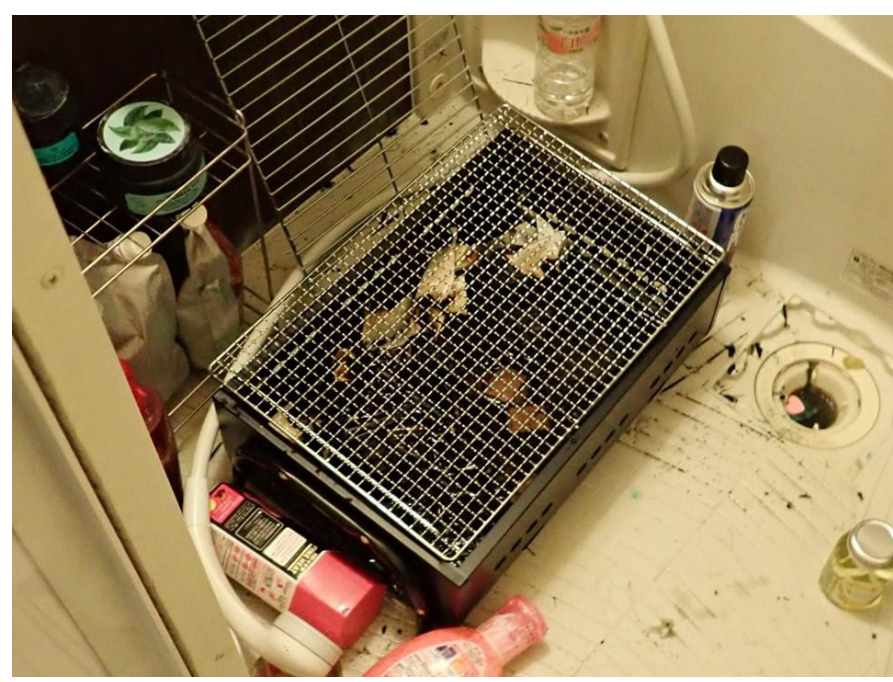

The patient placed the charcoal on a steel mesh grate and ignited them from the bottom using the barbecue stove.

Figure 1. The barbecue stove in the bathroom

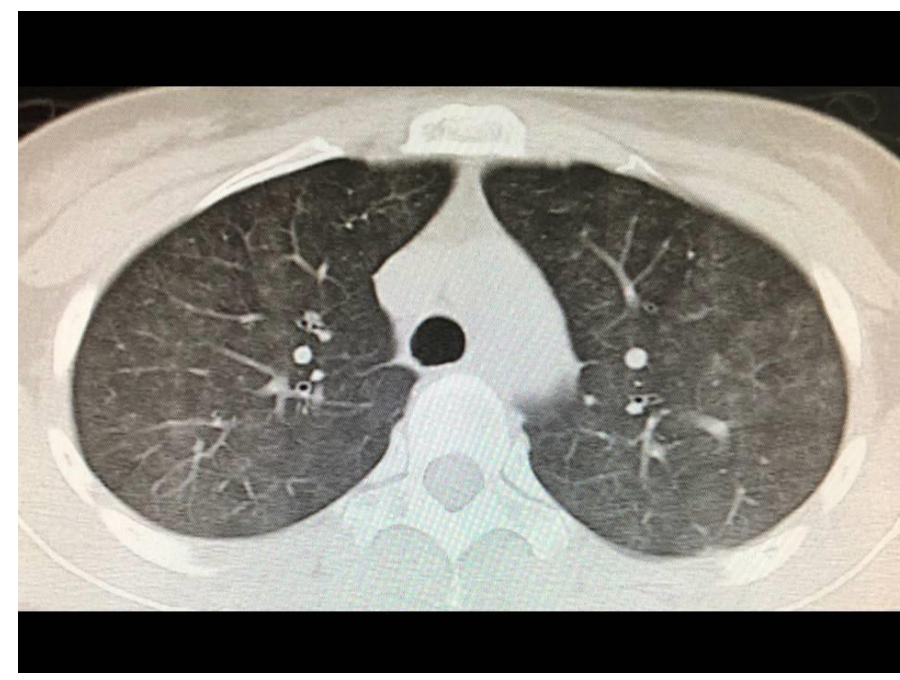

CT shows a diffuse patchy ground glass appearance.

Figure 2. Thoracic computed tomography (CT) on arrival

\begin{tabular}{|l|l|l|l|}
\hline Arterial blood gas (15 L/minute oxygen) & 7.396 & $\mathrm{PCO}_{2}$ & $43.2 \mathrm{mmHg}$, \\
\hline $\mathrm{pH}$ & $422.5 \mathrm{mmHg}$ & $\mathrm{HCO}_{3}-$ & $25.9 \mathrm{mmol} / 1$ \\
\hline $\mathrm{PO}_{2}$ & $1.1 \mathrm{mmol} / 1$ & Lactate & $11.0 \mathrm{mmol} / 1$ \\
\hline Base excess & $14.5 \%$ & Methemoglobin & $11.1 \%$ \\
\hline Carboxyhemoglobin & \multicolumn{5}{l|}{} \\
\hline Blood count & $7100 / \mu \mathrm{l}$ & Hemoglobin & $10.9 \mathrm{~g} / \mathrm{dl}$ \\
\hline White blood cell count & $23.7 \times 104 / \mu \mathrm{l}$ & & \\
\hline Platelet count & \multicolumn{5}{l}{} \\
\hline Serum biochemistry & $6.2 \mathrm{~g} / \mathrm{dl}$ & Total bilirubin & $0.6 \mathrm{mg} / \mathrm{dl}$ \\
\hline Total protein & $16 \mathrm{IU} / 1$ & Alanine aminotransferase & $9 \mathrm{U} / 1$ \\
\hline Aspartate aminotransferase & $178 \mathrm{IU} / \mathrm{L}$ & Alkaline Phosphatase & $120 \mathrm{IU} / \mathrm{L}$ \\
\hline Lactate dehydrogenase & $14.7 \mathrm{mg} / \mathrm{dl}$ & Creatinine & $0.60 \mathrm{mg} / \mathrm{dl}$ \\
\hline Blood urea nitrogen & $139 \mathrm{mEq} / 1$ & Potassium & $3.7 \mathrm{mEq} / 1$ \\
\hline Sodium & $103 \mathrm{mEq} / \mathrm{l}$ & C reactive protein & $0.02 \mathrm{mg} / \mathrm{dl}$ \\
\hline Chloride & \multicolumn{4}{l}{} \\
\hline
\end{tabular}

Table1. The results of the laboratory analysis

The incomplete combustion of burning charcoal can produce carbon dioxide and carbon monoxide. However, there have been no reports on lung edema directly induced by carbon dioxide or carbon monoxide. Cardiac toxicity after carbon monoxide poisoning can result in arrhythmia, heart failure and myocardial infarction following the formation of lung edema [3]. However, this case was not complicated with such cardiac disturbances. The burning of iron burning, it can produce various iron oxides, including $\mathrm{Fe}_{3} \mathrm{O}_{4}, \mathrm{Fe}_{2} \mathrm{O}_{3}$, and $2 \mathrm{FeO}$. The inhalation of iron oxide particles containing soluble iron can induce mild pulmonary inflammation and lead to altered alveolar epithelial integrity and altered gas exchange [4,5]. Accordingly, the lung edema in the present case was thought to have been induced by the inhalation of iron oxide particles, which were produced by the burning of the steel mesh grate in the sealed bathroom. Another possible mechanism through which lung edema may form is hypoxia-induced lung edema
[6,7]. Intrapulmonary arteries constrict in response to alveolar hypoxia, diverting blood to better-oxygenated lung segments, thereby optimizing the supply of oxygen [7]. However, this induces an increase in the pulmonary artery pressure. The rapid increase in pulmonary artery pressure stresses and distends the arterial walls. Within a short time, these changes exceed the load capacity of the pulmonary artery resistance, resulting in the rupture of the basement membrane and the alveolar-capillary barrier, and the formation of lung edema [7]. However, hypoxia-induced lung edema is associated with diffuse edema. In contrast, the lung edema in the present case appeared as edema in each bronchiole segment, which was compatible with lung edema induced by the inhalation of iron oxide particles. Accordingly, in the present case, we consider the possibility of hypoxia-induced lung edema to be minimal. 
There has been no reports on the induction of methemoglobinemia by carbon dioxide or carbon monoxide. Methemoglobin is formed by the oxidation of ferrous (FeII) heme to the ferric (FeIII) state; the mechanisms through which this occurs are complex. Most cases are due to one of three processes [8]. The first mechanism involves the direct oxidation of ferrous hemoglobin, which is oxidized to form ferric methemoglobin, involving the transfer of electrons from ferrous heme to the oxidizing compound. This mechanism proceeds most readily in the absence of oxygen [8]. The second mechanism involves indirect oxidation, a process of co-oxidation that requires hemoglobin-bound oxygen and is involved, for example, in nitrite- or hydrogen sulfideinduced methemoglobinemia [8]. The third mechanism involves the biotransformation of a chemical into an active intermediate that initiates methemoglobin formation by a variety of mechanisms. This is the means by which most aromatic compounds, such as amino- and nitroderivatives of benzene, produce methemoglobin [8]. In cases involving fire, methemoglobinemia has been reported to have been caused by the inhalation of hydrogen cyanide liberated from burning plastics [9]. In the present case, the barbecue stove might have been contaminated with blood or meat, both of which contain proteins. When protein or amino acids are burnt, they release carbon dioxide, carbon monoxide, water, nitrogen oxides and trace amounts of hydrogen sulfide. Accordingly, hypoxia-ionized iron oxide, nitrogen oxides and/or hydrogen sulfide may have contributed to the development of methemoglobin in the present case.

Hyperbaric oxygen therapy is a useful treatment for patients with carbon monoxide poisoning, as well as those with methemoglobinemia $[10,11]$. and may be useful for lung edema under specific conditions [12-14]. However, hyperbaric oxygen therapy itself can induce lung edema $[15,16]$. Accordingly, the physician should pay attention to the general physical condition during hyperbaric oxygen therapy for patients with lung edema.

\section{Conclusion}

This is the first case of carbon monoxide poisoning, methemoglobinemia and lung edema without heart failure after a suicide attempt in which an individual burned charcoal on a steel mesh grate. Physicians should pay attention to the burned materials and the systemic condition of the patient when treating patients who have attempted suicide by charcoal burning.

\section{Funding}

This manuscript obtains financial support from the Ministry of Education, Culture, Sports, Science and Technology (MEXT)-Supported Program for the Strategic Research Foundation at Private Universities, 2015-2019 concerning [The constitution of total researching system for comprehensive disaster, medical management, corresponding to widescale disaster].

\section{Conflict of interest}

The authors declare no conflicts of interest in association with the present study.

\section{Acknowledgements}

\section{None.}

\section{References}

1. Ministry of Health, Labour and Welfare. Situation of Suicide in Heisei 27 years. 2015;18-30. https://www.mhlw.go.jp/wp/hakusyo/jisatsu/16/dl/1-06.pdf

2. Chang SS, Chen YY, Yip PS, et al.『Regional changes in charcoal-burning suicide rates in East/Southeast Asia from 1995 to 2011: a time trend analysis. PLoS Med. 2014;11(4):e1001622.

3. Lee JH, Kim HS, Park JH, et al. Incidence and clinical course of left ventricular systolic dysfunction in patients with carbon monoxide poisoning. Korean Circ J. 2016;46(5):665-671

4. Sadeghi L, Yousefi Babadi V, Espanani HR. WToxic effects of the Fe2O3 nanoparticles on the liver and lung tissue. Bratisl Lek Listy. 2015;116(6):373-378.

5. Wang L, Wang L, Ding W, et al. \Acute toxicity of ferric oxide and zinc oxide nanoparticles in rats. J Nanosci Nanotechnol. 2010;10(12):8617-2864.

6. Dunham-Snary KJ, Wu D, Sykes EA, et al. Hypoxic pulmonary vasoconstriction from molecular mechanisms to medicine. Chest. 2017;151(1):181-192.

7. Li Y, Han J, Chen Y, et al.囚p-Coumaric acid as a prophylactic measure against normobaric hypoxia induced pulmonary edema in mice.『Life Sci. 2018;211:215223.

8. Bradberry SM. Occupational methaemoglobinaemia. Mechanisms of production features, diagnosis and management including the use of methylene blue. Toxicol Rev. 2003;22(1):13-27.

9. Hoffman RS, Sauter D. Methemoglobinemia resulting from smoke inhalation. Vet Hum Toxicol. 1989;31(2):168-170.

10. Rose JJ, Wang $\mathrm{L}, \mathrm{Xu} \mathrm{Q}$, et al. Carbon monoxide poisoning: pathogenesis, management, and future directions of therapy. Am J Respir Crit Care Med. 2017;195(5):596-606.

11. Cho Y, Park SW, Han SK, et al.『A case of methemoglobinemia successfully treated with hyperbaric oxygenation monotherapy.खJ Emerg Med. 2017;53(5):685-687.

12. Chen HM, Shyr MH, Ueng SW, et al. Hyperbaric oxygen therapy attenuates pancreatic microcirculatory derangement and lung edema in an acute experimental pancreatitis model in rats. Pancreas. 1998;17(1):44-49.

13. Kurygin GV, Blandinskaia NF, Mikhaĭlov VP. Hyperbaric oxygenation in the treatment of neurogenic pulmonary edema. Anesteziol Reanimatol. 1981;(6):3234. in Russian

14. Kurygin GV, Polikarpov VV, Fafurina ML. Effects of hyperbaric oxygenation thalamonal and their combination on pulmonary edema in experimental embolism of blood vessels of the lesser circulation. Grudn Khir. 1989;(4):36-39. in Russian

15. Fan $D, L v Y, H u H$, et al. Severe pulmonary edema following hyperbaric oxygen therapy for acute carbon monoxide poisoning: a case report and clinical experience. Undersea Hyperb Med. 2017;44(3):287-291.

16. Weaver LK, Churchill S. Pulmonary edema associated with hyperbaric oxygen therapy. Chest. 2001;120(4):1407-1409. 